\title{
READINESS ASSESSMENT OF PATIENTS WITH ARTERIAL HYPERTENSION TO THE APPLICATION OF TELEMEDICAL TECHNOLOGIES
}

\author{
Inna Berdnyk \\ Department of Internal Medicine ${ }^{l}$ \\ berdnik.inno4ka@gmail.com \\ Volodymyr Bulda \\ Department of Internal Medicine \\ Educational and Scientific Center "Institute of Biology and Medicine» \\ of Taras Shevchenko National University of Kyiv \\ Akademika Hlushkova ave., 2, Kyiv, Ukraine, 03127 \\ Volodymyr Bogomaz \\ Department of Internal Medicine ${ }^{l}$ \\ ${ }^{1}$ Bogomolets National Medical University \\ T. Shevchenko blvd., 13, Kyiv, Ukraine, 01601
}

\begin{abstract}
This article presents original data on patients' awareness of arterial hypertension and their readiness to use telemedicine technologies.

The aim: to study the factors that may affect the effectiveness of diagnosis and treatment of patients with arterial hypertension $(\mathrm{AH})$ through the use of telemedicine technologies.

Materials and methods: this study involves 336 outpatients and indoor patients diagnosed with arterial hypertension. Anonymously, using a questionnaire, were assessed patients' awareness of their diagnosis, access to the Internet, and the ability to remotely control of blood pressure.

Results: only about a third of all respondents systematically took the recommended antihypertensive therapy daily. Among them, the vast majority were indoor patients ( $82 \%$ ). We found a direct dependence between the regularity to use the antihypertensive therapy and the interest in the use of telemonitoring of blood pressure (Spearman correlation coefficient +0.59 ). There is a low awareness of patients about the possibilities of remote monitoring of blood pressure (only $11 \%$ ), the vast majority of patients (60\%) for the first time learned about such technologies. Among our respondents, a statistically significant dependence was found between the age of patients and interest in telemonitoring blood pressure at a significance level of $p<0.01\left(\chi^{2}-26.119\right.$, and the critical value of $\chi^{2}$ significance level $p=0.01$ is 9.21).

Conclusions: the main sources of information for patients with arterial hypertension are primary care physicians (family doctors, therapists) and the Internet. Limited access of patients to the Internet can negatively affect over introduction of telemedicine technologies for the management of arterial hypertension, despite the great interest of patients and society.
\end{abstract}

Keywords: arterial hypertension, high blood pressure, telemonitoring of blood pressure, prevalence of hypertension.

DOI: $10.21303 / 2504-5679.2021 .001601$

\section{Introduction}

Arterial hypertension (AH) remains one of the most common non-communicable diseases worldwide. The World Health Organization (WHO) estimates that one in four men and one in five women have $\mathrm{AH}$, which is a total of about 1.2 billion people worldwide. According to the updated ESH/ESC guidelines, in 2018 about 150 million of the population in Central and Eastern Europe had high blood pressure, and by 2025 a further increase in the number of patients is expected [1]. Experts of the WHO MONICA project claim that the countries of Eastern Europe and, in particular, Ukraine, contribute the lion's share to the global incidence of a hypertension disease. The prevalence of $\mathrm{AH}$, and especially the proportion of uncontrolled hypertension in these countries, is much higher and can reach $65 \%[2,3]$.

International differences in the prevalence of AH are quite significant and also tend to increase. In particular, according to datum by Katherine T. Mills et al., from 2000 to 2010, the prevalence 
of hypertension decreased by $2.6 \%$ in high-income countries, but increased by as much as $7.7 \%$ in low- and middle-income countries [4]. During the same period, in high-income countries, the percentage of patients' awareness of their disease (up to $67.0 \%$ ) and the need for further control (up to $28.4 \%$ ) is significantly increased. It was noted that the regularity of antihypertensive medicine in low- and middle-income countries has even decreased slightly (8.4\% vs. $7.7 \%$ ) [5].

According to a report by the WHO European Branch, non-communicable diseases are the cause of $86 \%$ of all deaths and $77 \%$ of disability in the European region. This is especially important for the elderly, who in most cases have comorbid pathology, which worsens the prognosis and control of arterial hypertension [6,7]. It is expected that disappointing trend to continue for at least the next twenty years [8].

According to the statistics of the Ministry of Health of Ukraine in 2018 the number of patients with AH in the country was more than 12 million. The highest prevalence was observed in the age group 55-64 years (among rural residents: $80.0 \%$ men, $72.0 \%$ women; among urban residents: $65.9 \%$ of men, $76.2 \%$ of women) [9]. The incidence of diseases of the circulatory system in 2018 in Ukraine amounted to 52923,6 per 100 thousand population. Every year, more than 400,000 Ukrainians die from coronary vascular diseases (CVD). Mortality from diseases associated with AH continues to hold the top spot by a significant margin in the mortality structure of the population of Ukraine, despite the availability of effective pharmaceutical products and government programs that have increased their availability to citizens [10].

Taking this into account, the modification of $\mathrm{AH}$ is one of the main tasks of the practical level of health care. According the data of a meta-analysis of randomized trials by Dena Ettehad et al., a decrease in systolic arterial blood pressure by $10 \mathrm{~mm}$ column of mercury reduced the risk of major coronary vascular diseases in general - by $20 \%$, ischemic heart disease - by $17 \%$, stroke by $27 \%$, heart failure - by $28 \%$ and all-cause mortality - by $13 \%$ [11].

Blood pressure (BP) telemonitoring (TM) is seen as a patient management strategy that allows remote transmission of patient health status to a doctor over the Internet. Several incidence studies suggest that regular use of TM is associated with significant and prolonged BP lowering, especially in high-risk patients. The use of telemedicine technologies can help improve the patient's commitment to self-control, improve compliance and communication with the doctor, timely adjustment of treatment if necessary $[12,13]$.

New digital tools and mobile applications that are used to manage health status, have many aspects and require careful research and further analysis, in particular, regarding their effectiveness compared to traditional methods, assessments of possible medico-social and financial-economic benefits [14].

Despite the emergence of new medicine and their combinations, technical progress and availability of devices for measuring arterial blood pressure - the high prevalence of arterial hypertension in Ukraine and the number of its complications indicates a lack of already performed actions and requires the development of new technologies for arterial hypertension management [15]. The medical literacy of citizens, in particular the elderly and rural residents, the unification of approaches to the management of such patients at all levels, the disembarrassment and timeliness of seeking affordable medical attendance, strict adherence to medical recommendations need more attention [16].

The aim of the research: is to study the factors that may affect the effectiveness of diagnosis and treatment of patients with arterial hypertension through the use of telemedicine technologies.

\section{Materials and methods}

The study was conducted in 2019-2020 on the basis of five medical centers of primary and secondary health care (Republican Clinical Hospital: outpatient department and inpatient departments, Family Medicine Outpatient Clinic in Kyiv and in Smila, department of «Emergency Medical Care» in Smila, Cherkasy region) in two cities of Ukraine - Kyiv and Smila. The inclusion criteria were: patients with a previous diagnosis of $\mathrm{AH}$ who received medical attendance; age of patients - older than 18 years; absence of significant visual impairments that would make it impossible to work correctly with the questionnaire; patient consent. Patients' awareness of AH, Internet access, and remote blood pressure monitoring were assessed anonymously using a specially 
designed questionnaire. Patients were provided with a questionnaire in paper or electronic form with 10 questions with several variants for answering them and the ability to record comments. By age, patients were divided into 3 groups: 18-44 years (the average age of patients was 33.74 \pm 3.01 ), 45-65 years (the average age of patients was $58.25 \pm 3.86$ ) and older 66 years (the average age of patients was $68 \pm 2.91)$.

This study was approved by the ethics commission of Bogomolets National Medical University (protocol No. 10 on April 21, 2020).

This study was conducted in accordance with the Declaration of Helsinki and informed consent was obtained from all patients.

The distribution of respondents by stage of $\mathrm{AH}$ was carried out according to the European Hypertension guidelines. A number of questions in the questionnaire concerned patient awareness, regularity of therapy and personal interest in telemedicine technologies. A total of 343 questionnaires were collected, of which 336 questionnaires were found to be correctly completed and taken for statistical processing. Statistical processing of information was performed using Student's t-test and Pearson's $\chi^{2}$, the critical value of which was considered to be $<0.05$.

The keywords «High blood pressure», «Arterial hypertension prevalence», «WHO hypertension» and «European Hypertension Guidelines» were used for bibliographic search of information on arterial hypertension. The search was performed in the following databases: Web of Science, Scopus, MEDLINE, Medscape, PubMed, irbis-nbuv, Google Scholar, BASE, for the period 2015-2020. A total of 18 sources were selected and analyzed in English and Ukrainian.

\section{Results}

Among the respondents, $43.15 \pm 2.7 \%$ were indoor patients (145 patients) and $56.85 \pm 2.7 \%-$ (191 patients) outpatients. The gender distribution was dominated by women, who accounted for $57.12 \pm 2.69 \%$. Both women and men were dominated by the middle-aged group (45-65 years) $60.56 \pm 2.66 \%$ and $64.43 \pm 2.61 \%$, respectively (without a statistically significant difference). There were significantly fewer men $(p<0.05)$ over the age of 65 (Fig. 1), which is partly explained by the general gender disparities in the Ukrainian population.

Most patients had stage II of AH $(54.82 \pm 2.71 \%)$. Stage I of AH was statistically more common in the younger age group and mainly in urban residents. At that time, rural residents had only stage II and III disease, which may be due to late treatment and registration, difficult access to timely medical attendance and basic diagnosis (Fig. 2).

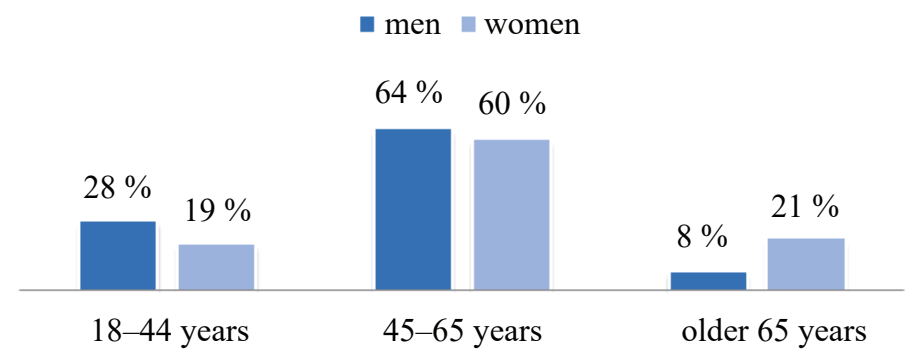

Fig. 1. Age and gender distribution of respondents

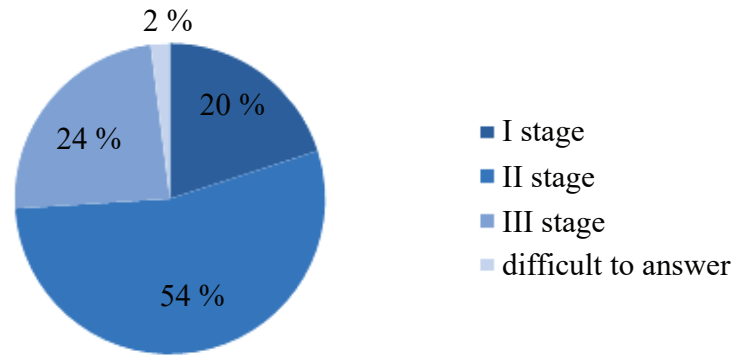

Fig. 2. Distribution of patients by stages of arterial hypertension 
It was found that the dependence between age and adherence to medicine treatment was not statistically significant among the surveyed patients $(p>0.05)$.

According to the questionnaire, only about a third of all respondents (124 patients) systematically took the recommended antihypertensive therapy daily. Among them, the vast majority were inpatients $(82.02 \pm 2.81 \%)$, which may indicate a better adherence to treatment of patients with severe clinical course. At the same time, $38.65 \pm 2.65 \%$ of respondents took «medication on demand» or did not take it in general, and among outpatients and those who sought emergency medical attendance, there were statistically more $(p<0.05)$ (Fig. 3). We also found a direct dependence between the regularity of antihypertensive therapy and interest in the use of telemonitoring of BP (Spearman correlation coefficient +0.59 ), which may indicate a high willingness of these patients to more careful control of BP.

The results of our study suggest that despite the proven effectiveness of lifestyle modifications and the availability of available antihypertensive medicine, the question of insufficient control of AH still remains open.

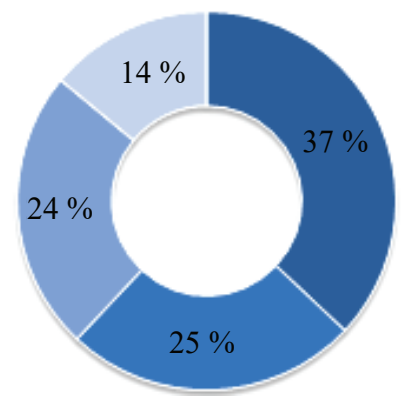

- daily take antihypertensive medicine

- sometimes forget to take antihypertensive medicine

- take antihypertensive medicine «if necesary»

don't take antihypertensive medicine

Fig. 3. Awareness of arterial hypertension, its features and possible complications

In our study, the dependence between age and adherence to medicine treatment was not statistically significant among the surveyed patients $(p>0.05)$.

Among the respondents of our study to the questionnaire «From whom you received information about $\mathrm{AH}$, the peculiarities of its course and possible complications» $70.26 \pm 2.82 \%$ answered «family doctor/therapist», $56.73 \pm 2.64 \%$ - «independently via the Internet», $14.12 \pm 1.84 \%$ - «neighbors/acquaintances», $8.47 \pm 1.51 \%$ - «media and television». It is noteworthy that almost every second patient used information about $\mathrm{AH}$, obtained both from the doctor and from the Internet. This, in our opinion, may indicate a lack of medical information (for example, due to lack of communication time), imperfect way of informing (in particular, the predominance of oral information over visual) or incomplete trust in information from medical staff in general with high interest of patients in knowledge of his/her disease. Then, to confirm this, 208 patients $(61.90 \pm 2.64 \%)$ said they wanted to know more about their diagnosis and only $12.55 \pm 1.8 \%$ - considered their knowledge sufficient.

We found low awareness of patients about the possibility of remote monitoring of BP among both indoor patients and outpatients (without a statistically significant difference, $p>0.05$ ), which was only $11.93 \pm 1.76 \%$. The rest of the respondents $(29.31 \pm 2.48 \%)$ were only theoretically aware of this and the vast majority of patients $(58.76 \pm 2.68 \%)$ learned about such technologies for the first time. We found a direct correlation relationship between the possibility of access to the Internet and the interest in remote monitoring of BP and doctor's consultation (Spearman's correlation coefficient +0.62 ).

Among our respondents we found a statistically significant dependence between the age of patients and interest in telemonitoring BP at a significance level of $p<0.01\left(\chi^{2}-26.119\right.$, and the critical value of $\chi^{2}$ significance level $p=0.01$ is 9.21 ).

\section{Discussion}

Administrative and financial barriers to the health care system, problems of patient-physician interaction, and low public awareness remain key obstacles to improving the health of patients with hypertension. The study of patients' commitment to the control and treatment of AH remains relevant for all countries. Then, according to the results of a systematic analysis of studies 
in 90 countries, there is a relatively high level of public awareness about AH in high and middleincome countries in Eastern Europe, while this indicate is much lower in European countries of the former Soviet Union (Ukraine, Belarus, Russia). The results of a study of BP and coronary vascular diseases (BP-CARE) in Eastern and Central Europe showed that out of 7860 patients with hypertension disease, only $25 \%$ had regular BP monitoring. At that time, only $27 \%$ of patients receiving antihypertensive treatment achieved the target BP level [8, 17].

In general, awareness of AH in Ukraine has increased somewhat recently. If in the mid-90s only a third of men and a little more than half of women knew about their AH, today $60.0 \%$ of men and $68.0 \%$ of women know that they have high BP. However, despite the improvement of the population's awareness of AH, the optimal results of BP control have not yet been achieved [18]. This may be due to the patient, the doctor or the medicine. That is why the approach to solving the problem must be comprehensive. Influencing comprehensively on all three links will achieve the maximum result.

The term «compliance» is often used in the medical literature and means the readiness, ability, desire and obligation of the patient to follow the doctor's prescription, including not only pharmacological treatment, but also the recommended behaviour (diet, lifestyle modification, care own health status). Then, according to data by S. Ya. Dotsenko (2013), uncontrolled AH is characterized by disorders of patient-dependent attachment with low awareness of complications of $\mathrm{AH}$ and the insecurity of risk factors, accompanied by insufficient BP, infrequent visits to the doctor, irregular intake or self-administration of antihypertensive medicine [18].

It is well known that age is a risk factor for coronary vascular diseases (CVD). However, in a study by Xin Lv et al. [19] the level of awareness and attachment to the treatment of AH was significantly lower in young patients than in middle-aged patients (without statistical difference), but significantly lower than in older patients $(p<0.05)$. This can be explained by lifestyle and habits, frivolous perception of the disease, active social life, timeless for their own health, etc. In addition, it was noted that $54 \%$ of patients learned about their high BP only when complications associated with AH appeared. Educational work, information policy and promotion of the annual medical examination should become a priority in the primary prevention of hypertension [19].

The European guidelines for the management of patients with $\mathrm{AH}$ for the first time recognize that the use of home and outpatient arterial blood pressure monitoring is an important tool for both diagnosis and treatment of hypertension. It is also noted that these research methods should be used in patients with persistent hypertension to exclude the «white coat effect» [1].

It is known that patients with $\mathrm{AH}$ can be divided into several subtypes according to the indicators of outpatient and home BP measurement. Then, in a nationwide multicenter prospective study THAI HBPM evaluated the prevalence of different subtypes and the effectiveness of the use of TM technologies. It was found that among patients receiving the recommended treatment, $23.3 \%$ had hypertension of «white coat» and 9.6\% - masked uncontrolled arterial hypertension. Similar results were found in another study (Asia BP@Home study). Telemonitoring, as opposed to home arterial blood pressure measurement, allows to monitor and analyze the obtained indicators by medical staff remotely, to improve the administration of such patients by titrating the dose of medicine and feedback without face consultation and minimizing the patient's stress response [20].

To confirm this, the results of a meta-analysis of 23 randomized studies, which found that TM showed a statistically significant higher efficiency of BP reduction in both outpatient measurement and Holter monitoring of BP compared with periodic self-home measurement without data [12, 14]. It was shown that health care costs were significantly higher in the TM group $(p<0.01)$, but similar to those incurred in the normal observation group, when the costs of technology are minimal, but significant for health care. In terms of economic feasibility, health care costs were significantly $(P<0.01)$ higher in the TM group $(+662.92 ; 95 \%$ DI, +540.81 to +785.04 euros per patient $)$, but similar those received by patients in the usual observation group, when the cost of technology are minimal, but significant for medical care $(-12.4$; $95 \%$ IC, -930.52 to +906.23 euros $[P=0.767])$ [12].

However, in Ukraine the data is different. According to one study [21] of the use of the Internet for medical purposes, the level of computer literacy of urban patients was quite high $(75.7 \%$ of respondents personally worked on a computer, including $97.8 \%$ of them - with using the Internet), but with increasing age of patients the frequency of Internet use is decreased statistically significantly. 
Among patients who had access to the Internet, $92.6 \%$ of people sought medical information there. In addition, it was determined that $89 \%$ of respondents found the information they needed online, and most of them used it to make decisions. In particular, more than twenty percent of patients used the Internet to verify the correctness of advice and prescriptions.

It can be concluded that not only global but also regional differences in awareness, commitment to treatment and control of AH are quite wide and growing. Published research confirms that TM has significant potential to increase adherence to treatment and reduce to health care costs, especially in terms of the long perspective. However, there is a high level of heterogeneity in published data, which somewhat reduces the value of the evidence provided and requires further research.

Study limitations. The study was conducted in a questionnaire format, and therefore it is not possible to track the dynamic changes in answers. In addition, only the subjective attitude is displayed without support by objective data. It is not possible to make a correlation with the data of the patient's outpatient card.

Prospects for further research. New digital devices and mobile applications used for health management have many aspects and require careful research and further analysis, in particular, regarding their effectiveness compared to traditional methods, assessment of possible medical, social and financial and economic benefits. As cardiovascular diseases in general and arterial hypertension in particular occupy leading positions in the structure of morbidity and mortality of the population of Ukraine, improving the management of these diseases will be important for the health care system. The development of a new method of blood pressure control through telemonitoring will be able to improve the patient's adherence to blood pressure control and medication.

\section{Conclusions}

1. Patients with arterial hypertension have a high level of interest in information about their own disease and $61.90 \pm 2.64 \%$ patients wanted to know more about their diagnosis. The main sources of information were primary care physicians (family physicians, therapists) and the Internet in $70.26 \pm 2.82 \%$ and $56.73 \pm 2.64 \%$ of patients, respectively.

2. There is a direct strong relationship between the possibility of Internet access and interest in remote monitoring of blood pressure and doctor's consultation (Spearman's correlation coefficient +0.62 ), due to greater awareness of patients about modern devices in large cities and the likely limitation in small towns with poor internet coverage.

3. Statistically greater interest in TM technologies in the group of young people than people over 65 who have access to the Internet $(p<0.01)$ may contribute to better and faster involvement of these patients in the treatment of hypertension and promote better interaction with the doctor and commitment to treatment.

\section{Conflict of interests}

The authors declare that they have no conflicts of interest.

\section{References}

[1] Williams, B., Mancia, G., Spiering, W., Agabiti Rosei, E., Azizi, M., Burnier, M. et. al. (2018). 2018 ESC/ESH Guidelines for the management of arterial hypertension: The Task Force for the management of arterial hypertension of the European Society of Cardiology and the European Society of Hypertension. European Heart Journal, 39 (33), 3021-3104. doi: http:// doi.org/10.1093/eurheartj/ehy339

[2] Stanaway, J. D., Afshin, A., Gakidou, E., Lim, S. S., Abate, D., Abate, K. H. et. al. (2018). Global, regional, and national comparative risk assessment of 84 behavioural, environmental and occupational, and metabolic risks or clusters of risks for 195 countries and territories, 1990-2017: a systematic analysis for the Global Burden of Disease Study 2017. The Lancet, 392 (10159), 1923-1994. doi: http://doi.org/10.1016/s0140-6736(18)32225-6

[3] WHO MONICA Project Principal Invest. (1988). The world health organization monica project (monitoring trends and determinants in cardiovascular disease): A major international collaboration. Journal of Clinical Epidemiology, 41 (2), $105-114$. doi: http://doi.org/10.1016/0895-4356(88)90084-4

[4] Vos, T., Abajobir, A. A., Abate, K. H., Abbafati, C., Abbas, K. M., Abd-Allah, F. et. al. (2017). Global, regional, and national incidence, prevalence, and years lived with disability for 328 diseases and injuries for 195 countries, 1990-2016: a systematic 
analysis for the Global Burden of Disease Study 2016. The Lancet, 390 (10100), 1211-1259. doi: http://doi.org/10.1016/ s0140-6736(17)32154-2

[5] Mills, K. T., Bundy, J. D., Kelly, T. N., Reed, J. E., Kearney, P. M., Reynolds, K. et. al. (2016). Global Disparities of Hypertension Prevalence and Control A Systematic Analysis of Population-Based Studies From 90 Countries. Circulation, 134 (6), 441-450. doi: http://doi.org/10.1161/circulationaha.115.018912

[6] Hypertension (2019). World Health Organization. Available at: https://www.who.int/news-room/fact-sheets/detail/hypertension

[7] Regional Office for Europe. High blood pressure - country experiences and effective interventions utilized across the European Region (2019). World Health Organization. Available at: http://www.euro.who.int/_data/assets/pdf_file/0008/185903/ e96816.pdf

[8] Foreman, K. J., Marquez, N., Dolgert, A., Fukutaki, K., Fullman, N., McGaughey, M. et. al. (2018). Forecasting life expectancy, years of life lost, and all-cause and cause-specific mortality for 250 causes of death: reference and alternative scenarios for 2016-40 for 195 countries and territories. The Lancet, 392 (10159), 2052-2090. doi: http://doi.org/10.1016/ s0140-6736(18)31694-5

[9] Sirenko, Yu. M. (2018). Pro novi yevropeiski rekomendatsii z arterialnoi hipertenzii pislia yikh pershoi prezentatsii (komentar). Arteryalnaia hypertenzyia, 3.59, 19-22. Available at: http://www.mif-ua.com/archive/article/46277

[10] Dzyuba, O. M., Pazynych, L. M., Sitenko, O. R., Kryvenko, Y. M. (2017). The actual questions of global burden of diseases in Ukraine. Bulletin of Social Hygiene and Health Protection Organization of Ukraine, 2, 8-14. doi: http://doi.org/10.11603/ 1681-2786.2017.2.8101

[11] Ettehad, D., Emdin, C. A., Kiran, A., Anderson, S. G., Callender, T., Emberson, J. et. al. (2016). Blood pressure lowering for prevention of cardiovascular disease and death: a systematic review and meta-analysis. The Lancet, 387 (10022), 957-967. doi: http://doi.org/10.1016/s0140-6736(15)01225-8

[12] Parati, G., Dolan, E., McManus, R. J., Omboni, S. (2018). Home blood pressure telemonitoring in the 21st century. The Journal of Clinical Hypertension, 20 (7), 1128-1132. doi: http://doi.org/10.1111/jch.13305

[13] Tucker, K. L., Sheppard, J. P., Stevens, R., Bosworth, H. B., Bove, A., Bray, E. P. et. al. (2017). Self-monitoring of blood pressure in hypertension: A systematic review and individual patient data meta-analysis. PLOS Medicine, 14 (9), e1002389. doi: http://doi.org/10.1371/journal.pmed.1002389

[14] Omboni, S., Gazzola, T., Carabelli, G., Parati, G. (2013). Clinical usefulness and cost effectiveness of home blood pressure telemonitoring: meta-analysis of randomized controlled studies. Journal of Hypertension, 31 (3), 455-468. doi: http:// doi.org/10.1097/hjh.0b013e32835ca8dd

[15] Bulda, V., Bogomaz, V., Berdnyk, I. (2019). The use of telemedical technologies in management of hypertension. Bulletin of Problems Biology and Medicine, 1 (2), 20-24. doi: http://doi.org/10.29254/2077-4214-2019-1-2-149-20-24

[16] Ionov, M. V., Zvartau, N. E., Konradi, A. O. (2019). Status of hypertension in Russia and Eastern Europe. E-Journal of Cardiology Practice. Available at: https:/www.escardio.org/Journals/E-Journal-of-Cardiology-Practice/Volume-17/ status-of-hypertension-in-russia-and-eastern-europe

[17] Reuter, H., Jordan, J. (2019). Status of hypertension in Europe. Current Opinion in Cardiology, 34 (4), 342-349. doi: http:// doi.org/10.1097/hco.0000000000000642

[18] Slascheva, T. G. (2018). Control of arterial blood pressure, factors associated with it and the possibility of its improvement in various unorganized populations of patients with arterial hypertension. Kyiv: National Scientific Center «M. D. Strazhesko Institute of Cardiology», 227.

[19] Lv, X., Niu, H., Qu, Y., Li, M., Li, L., Ma, X. et. al. (2018). Awareness, treatment and control of hypertension among hypertensive patients aged 18 to 59 years old in the northeast of China. Scientific Reports, 8. Available at: https://www.nature.com/ articles/s41598-018-34923-5

[20] Montrivade, S., Chattranukulchai, P., Siwamogsatham, S., Vorasettakarnkij, Y., Naeowong, W., Boonchayaanant, P. et. al. (2020). Hypertension Subtypes among Thai Hypertensives: An Analysis of Telehealth-Assisted Instrument in Home Blood Pressure Monitoring Nationwide Pilot Project. International Journal of Hypertension, 2020, 1-9. doi: http://doi.org/10.1155/2020/3261408

[21] Bohomaz, V. M., Sondak, M. S., Mohyla, O. I. (2016). Otsinka vykorystannia Internetu dlia medychnykh potreb patsiientamy mista Kyieva. Praktykuiuchyi likar, 3, 95-98. 